\title{
Occurrence of Plasmid-mediated AmpC $\beta$-lactamases among Enterobacter cloacae, Serratia marcescens and Citrobacter freundii in China \\ $\mathrm{J}_{\text {Cheng }}{ }^{1}, \mathrm{X}-\mathrm{J} \mathrm{Ma}{ }^{1}, \mathrm{~J} \mathrm{Sun}^{2}, \mathrm{Y} \mathrm{Ye}^{1}$
}

\begin{abstract}
Background: A total of 775 consecutive non-duplicate isolates of Enterobacteriaceae (534 E. cloacae, 137 S. marcescens and 104 C. freundii) were collected from 2005 to 2014 at 34 hospitals in Anhui Province, China.

Material and Methods: The detection of plasmid-mediated AmpC $\beta$-lactamases (pAmpCs) was based on the inhibitor screening method. Then, the association with other $\beta$-lactamases and mobile genetic elements, like class 1 integron, ISCRI and ISEcpl, were analyzed by molecular biology method.
\end{abstract}

Results: Among the total of 775 isolates, the prevalence of pAmpC was discovered to be $8.1 \%(63 / 775)$ overall. In this study, the presence of pAmpCs was significantly linked to other $\beta$-lactamases and mobile genetic elements, among which $b l a_{\mathrm{CTX}-\mathrm{M}}$ and class 1 integron were the most prevalent genotype.

Conclusion: Therefore, various combinations of $\beta$-lactamases and mobile genetic elements were detected in the study. Plasmids were demonstrated to be the main vehicles for the dissemination of $\mathrm{pAmpC}$ genes.

Keywords: class 1 integron, Enterobacteriaceae, plasmid-mediated AmpC $\beta$-lactamases

From: ${ }^{1}$ Department of Infectious Diseases, the First Affiliated Hospital of Anhui Medical University, 230022, Hefei, Anhui Province, PR China, ${ }^{2}$ Department of Science and Technology, Anhui University of Chinese Medicine, 230038, Hefei, Anhui Province, PR China.

Correspondence: Dr J Cheng, Department of Infectious Diseases, The First Affiliated Hospital of Anhui Medical University, Ying Ye, 230022, Hefei, Anhui Province, PR China. Fax: 86-551-62922713, email: yeying2@139.com 


\section{INTRODUCTION}

The $\beta$-lactams are a critically important class of antimicrobial agents utilized worldwide for the treatment of serious hospital- and community-acquired infections (1). The predominant mechanism for resistance to these antibiotics in gram-negative bacteria is the production of various plasmid-mediated $\beta$-lactamases, especially Ambler class A and class $\mathrm{C} \beta$-lactamase genes. Plasmid-mediated AmpC $\beta$-lactamases (pAmpCs) are derived from chromosomal ampC genes of several members of the family Enterobacteriaceae, including Citrobacter freundii, Enterobacter cloacae, Morganella morganii, and Hafnia alvei. These pAmpCs have been reported from various clinical isolates with increasing frequency (2). E. cloacae, $S$. marcescens and $C$. freundii are important nosocomial pathogens which naturally harbour chromosomal ampC genes. The data regarding coproduction of extended- spectrum $\beta$-lactamases (ESBLs) and pAmpCs in E. cloacae, S. marcescens and C. freundii are fragmentary (3-5). Several studies have described that the dissemination of genes encoding plasmid-mediated $\beta$-lactamase is mediated by mobile genetic elements carried by large transferable plasmids $(6,7)$. In light of the above facts, the present extensive study was planned to determine the prevalence of pAmpCs, the co-presence of ESBLs and mobile genetic elements, like class 1 integrons, ISCRI and ISEcpl in E. cloacae, S. marcescens and C. freundii isolates.

\section{MATERIALS AND METHODS}

\section{Bacterial isolates}

A total of 775 consecutive non-duplicate isolates of Enterobacteriaceae (534 E. cloacae, 137 S. marcescens and 104 C. freundii) were collected from 2005 to 2014 at 34 hospitals in Anhui Province, China. Anhui Province locates in eastern China with the permanent population of 
about 60.829 million and covers the area of 139,600 square kilometers. All hospitals were more than 800 beds. Species identification was performed with the Vitek 2 system (bioMérieux, Marcy l'Étoile, France) and confirmed with API 20E identification (bioMérieux, Marcy l'Étoile, France).

\section{Antimicrobial susceptibility testing}

For the clinical isolates and transconjugants analyzed in this study, the minimum inhibitory concentrations (MICs) for cefotaxime (CTX), ceftazidime (CAZ), cefoxitin (FOX), cefepime (FEP), imipenem (IPM), piperacillin-tazobactam (TZP), ciprofloxacin (CIP) and amikacin (AMK) were determined by an agar dilution method in accordance with the Clinical and Laboratory Standards Institute (CLSI) guideline, 2014 (8). The antimicrobial agents were provided as powders by National Institute for the Control of the Pharmaceutical and Biological Products, China. Quality control strains were E. coli ATCC 25922 and E. coli ATCC 35218 every batch of clinical isolates to ensure accurate and comparable performance of assays. Detection of ESBL confirmatory tests completed on the transconjugants was carried out with the Cation-adjusted Mueller-Hinton Broth Dilution Method as described by CLSI recommended.

\section{Conjugation experiments}

Conjugation was done as described by Barguigua using sodium azide-resistant E. coli J53 (E. coli $\mathrm{J} 53 \mathrm{AZ}^{\mathrm{R}}$ ) as the recipient strain (9). Donor strains in the logarithmic phase of growth were mixed with recipients in early stationary phase at a 1:10 ratio in Muller-Hinton broth (Oxiod, UK), and the conjugation mixtures were incubated at $37^{\circ} \mathrm{C}$ for $14 \mathrm{~h}$. Transconjugants were selected on tryptone soya agar supplemented with sodium azide $(100 \mu \mathrm{g} / \mathrm{ml}$, to inhibit growth of the donor strain) and FOX $(16 \mu \mathrm{g} / \mathrm{ml}$, to inhibit growth of the recipient strain), which were incubated for approximately $20 \mathrm{~h}$ at $37^{\circ} \mathrm{C}$. Tranconjugants were identified with 
API 20E and Vitek-2 system. Transconjugants producing AmpC-type $\beta$-lactamases were detected by PCR using purified plasmid DNA as the template, ultimately sequenced and tested for susceptibility as described above for the clinical isolates.

\section{Investigation of resistance determinants}

The detection of AmpC $\beta$-lactamase was based on the AmpC enzyme inhibitor screening method (10). Plasmids DNAs were extracted from the AmpC screened- positive isolates and transconjugants using the Qiagen plasmid purification kit (Qiagen, Hilden, Germany). Genes encoding 6 phylogenetic groups of acquired AmpC enzymes were sought with a multiplex PCR assay (11). Different $\beta$-lactamase genes (including $b l a_{\mathrm{CTX}-\mathrm{M}}, b l a_{\mathrm{TEM}}, b l a_{\mathrm{SHV}}$ and $\left.b l a_{\mathrm{OXA}}\right)$ and mobile elements such as class 1 integrons, ISCRI and ISEcpl were analyzed by PCR using primers as described previously for the isolates carrying pAmpCs $(9,12,13)$. Detection of the bla $_{\mathrm{IPM}}$ in pAmpCs producers was performed by PCR amplification. The purified PCR products were ligated with pUC118-Teasy vectors (TaKaRa, China), which were amplified in E. coli DH5a. All nucleotide sequences were sequenced by the dideoxy chain termination method using an ABI Prism 3730 sequence analyzer (Applied Biosystems, Foster City, CA). Sequence alignment was compared with the GenBank nucleotide database using the nucleotide BLAST program. The sequences of class 1 integron were analyzed by PCR-RFLP. After culturing the pAmpCs producers and ultrasonication, outer membrane proteins were extracted. Then, SDS-PAGE electrophoresis was performed and stained with Coomassie brilliant blue. The difference between the outer membrane proteins of clinical isolates was compared with E. cloacae ATCC 13047.

\section{Southern hybridizations of transconjugants}

The plasmids extracted from pAmpCs producers and their transconjugants by the rapid alkaline lysis protocol were digested with Pst I restriction enzyme (TaKaRa, China). The 
plasmid size was determined by comparison with plasmids of E. coli V517 (54, 5.6, 5.1, 3.9, 3.0, 2.7, and $2.1 \mathrm{~kb})$. DNA restriction fragment length polymorphisms were analyzed by the electrophoresis on the $0.8 \%$ agarose gel at $45 \mathrm{~V}$ for $16 \mathrm{~h}$ at $20^{\circ} \mathrm{C}$, transferred onto a nylon membrane (Amersham Biosciences, UK) with positive ion $\left(\right.$ Hybond- $\mathrm{N}^{+}$) overnight by the Southern hybridization technique. The membrance fixed by UV exposure was hybridized with PCR- generated probes whose sequences were specific internal regions of the $b a_{\mathrm{DHA}-1}$, $b l a_{\mathrm{ACT}-1}, b l a_{\mathrm{TEM}}, b l a_{\mathrm{SHV}}, b l a_{\mathrm{CTX}-\mathrm{M}-14}, b l a_{\mathrm{CTX}-\mathrm{M}-15}$, and $b l a_{\mathrm{OXA}-1}$ genes fragments, respectively. The nonradioactive enhanced chemilumine-scence random prime kit (Boster, China) was used to label the DNA probes $(20 \mathrm{ng} / \mathrm{mL})$ and for detection.

\section{RESULTS}

Rates of resistance to CTX, CAZ, FOX, FEP, IPM, TZP, CIP and AMK in relation to total clinical isolates were $62.3 \%, 47.0 \%, 63.7 \%, 5.6 \%, 13.4 \%, 13.3 \%, 22.4 \%$ and $48.2 \%$, respectively. Among the total of 775 clinical isolates, the prevalence of $\mathrm{pAmpC}$ carrier was found to be $8.1 \%(63 / 775)$ overall through the phenomenon of distorted inhibition zone around cefoxitin disk by the modified Hodge test. These pAmpCs were found in 54 of $534 E$. cloacae, 5 of 137 S. marcescens and 4 of 104 C. freundii. Conjugative transfer of ampC gene to $E$. coli $\mathrm{J} 53 \mathrm{AZ}{ }^{\mathrm{R}}$ was positive for 53 of the 63 selected isolates $(84.1 \%)$, including $46 E$. cloacae, 5 S. marcescens and 2 C. freundii, which suggested that the dissemination of AmpC determinants was mostly due to the transmission of plasmids. All pAmpCs producers tested were IMP sensitive except for 2 E. cloacae which produced IMP-1 metalloenzyme and lost outer membrane porin protein. MICs of FOX towards 63 pAmpCs producers ranged from 64 $\mathrm{mg} / \mathrm{L}$ to $>256 \mathrm{mg} / \mathrm{L}$. In addition, several of pAmpCs producers showed resistance to CIP and AMK. 53 transconjugants exhibited an increase in the MICs of $\beta$-lactams compared to the recipients. The transconjugants as well as $\mathrm{pAmpCs}$ producers present the similar resistance spectrum except for fluoroquinolones (Table 1). With regard to the genotypes, the most 
prevalent pAmpCs producers were $39 b l a_{\mathrm{DHA}-1}$, followed by $24 b l a_{\mathrm{ACT}-1}$. Then, the $b l a_{\mathrm{ampC}}$ genotypes of transconjugants were bla $_{\mathrm{DHA}-1}(\mathrm{n}=37)$, next to bla $_{\mathrm{ACT}-1}(\mathrm{n}=23)$ (Table 2).

Different other $\beta$-lactamases genes of 63 pAmpCs producers and 53 transconjugants screened by PCR using specific primers and identified by DNA sequencing were summarized in Table 3. Out of the pAmpC-positive isolates and transconjugants, a total of 23 E. cloacae and 19 transconjugants from E. cloacae were found to carry at least one of these $\beta$-lactamase genes. The dominant $\beta$-lactamase genes in this study were TEM-1 and SHV-5 genes, followed by CTX-M-14 and CTX-M-15. Notably, 12 isolates and 7 transconjugants harboring pAmpCs carried more than one type of other $\beta$-lactamases in different combinations. ESBL phenotypic confirmatory testing for 19 transconjugants from E. cloacae showed the prevalence were only $10.53 \%$. However, there were no positive results of ESBL found in other 34 transconjugants.

In 16 transconjugants carrying several of other $\beta$-lactamases genes, a single plasmid about $120-150 \mathrm{~kb}$ was extracted from per transconjugant. For a given restricted digestion, the subsequent Southern hybridization was with $b l a_{\mathrm{DHA}-1}, b l a_{\mathrm{ACT}-1}, b l a_{\mathrm{TEM}-1}, b l a_{\mathrm{SHV}-5}$, bla $_{\mathrm{CTX}-\mathrm{M}-14}$,

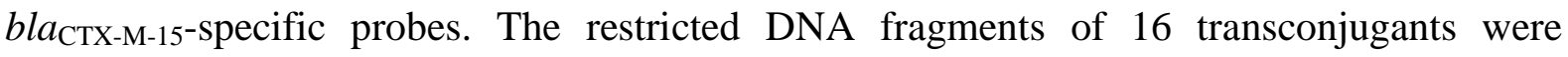
encoded by the same molecular weight fragment, approximately 70-90 kb. Corresponding to $16 \mathrm{pAmpCs}$ producers, there was a unique plasmid of about $120-150 \mathrm{~kb}$ detected from every clinical strain. Plasmid profiles were ran and then clinical isolates on the same blots as the transconjugants were used by Southern blot. The other 3 transconjugants carried 2 plasmids, which were the sizes of $120-140 \mathrm{~kb}$ and $60-80 \mathrm{~kb}$, respectively. Corresponding to 3 clinical strains, 2 plasmids about $120-140 \mathrm{~kb}$ and $60-80 \mathrm{~kb}$ were found from per pAmpCs producers. For 3 transconjugants carrying bla $_{\mathrm{OXA}-1}$, plasmids of approximately $60-80 \mathrm{~kb}$ were hybridized with the bla $a_{\mathrm{OXA}^{-}}$-specific probes. The electrophoretic display showed indistinguishable restriction patterns. Compared with other $\beta$-lactamases, it concluded that OXA-1 $\beta$-lactamase 
was mediated by the different plasmid. The same molecular weight fragment as the clinical strains, approximately $60-80 \mathrm{~kb}$, was detected in their transconjugants. To the transconjugant carrying $b l a_{\mathrm{DHA}-1}, b l a_{\mathrm{TEM}-1}, b l a_{\mathrm{CTX}-\mathrm{M}-14}$, and $b l a_{\mathrm{OXA}-1}, b l a_{\mathrm{DHA}-1}, b l a_{\mathrm{TEM}-1}$ and $b l a_{\mathrm{CTX}-\mathrm{M}-14}$ were encoded in the same molecular weight fragment, approximately $50 \mathrm{~kb}$, with specific probes. The same gels as the transconjugants with the clinical strains were detected with Southerns. Thus, $b l a_{\mathrm{DHA}-1}, b l a_{\mathrm{TEM}-1}$ and $b l a_{\mathrm{CTX}-\mathrm{M}-14}$ were also encoded in the identical plasmid in the isolates. To another transconjugant with $b l a_{\mathrm{DHA}-1}, b l a_{\mathrm{SHV}-5}, b l a_{\mathrm{CTX}-\mathrm{M}-14}$, and $b l a_{\mathrm{OXA}-1}, b l a_{\mathrm{DHA}-1}$, $b l a_{\mathrm{SHV}-5}$ and $b l a_{\mathrm{CTX}-\mathrm{M}-14}$ were also encoded in the same molecular weight fragment, approximately $55 \mathrm{~kb}$, with specific probes. In the clinical strains, the same blot about $55 \mathrm{~kb}$ as the transconjugants was observed in the hybridization image of restriction fragment.

By performing PCR, a total of pAmpCs positive isolates harboring intll integrase gene, ISCRI and ISEcpl were detected in 47.6\% (30/63), 39.7\% (25/63) and 19.0\% (12/63) respectively. Various combinations of observed genetic elements were more often detected in our study and intIl integrase gene plus ISCRI was found to be the most common combination in 11 pAmpC producers, followed by intII plus ISCRI plus ISEcpl in 10 pAmpC-positive clinical strains. None of the isolates harboured only ISEcpl or ISCRI plus ISEcpl combination. Highly similar frequencies of occurrence (55.6\%) to intll integrase gene were observed in 53 transconjugants, followed by ISCR1 (47.2\%) and ISEcpl (22.6\%). The structure of intII-bla $a_{\mathrm{amp}^{-}}$ISCRI-bla in integrons is the most frequently detected in 11 transconjugants carrying 2 kinds of $\beta$-lactamases genes. Then, the other 8 transconjugants encoding several of $\beta$-lactamases genes presented the structural forms of intI1-bla $a_{\mathrm{ampC}}-$ bla-ISCR1-ISEcp1 -bla.

\section{DISCUSSION}


To the best of our knowledge, this is the first systematic molecular survey reporting the prevalence of pAmpCs E. cloacae, S. marcescens and C. freundii isolates. A prevalence rate of pAmpCs was $8.1 \%$ overall for these chromosomal AmpC- producing isolates which implied the extensive dissemination of pAmpC-producing bacteria in China. Regrettably, many studies lay emphasis on inducible AmpC- producers or derepressed AmpC mutants and neglect pAmpCs that are often expressed in large amounts and are encoded by transposons that can be easily transferred among bacteria. This study demonstrated that most of the pAmpCs genes were successfully transferred on transferable plasmids to the recipients. An increase in the MICs of $\beta$-lactam was detected in the transconjugants compared to the recipients. It is suggested that the dissemination of the pAmpCs is mostly due to the transmission of plasmids by horizontal exchange. Consequently, the rapid spread of pAmpCs by plasmids raises clinical concern among Enterobacteriaceaes, especially $K$. pneumoniae and E. coli which are known for lacking or poorly expressing chromosomal AmpC $\beta$-lactamase genes (2). We detected a dominance of DHA-1 which had been mostly reported from Asia. It had been found existing in the plasmids of these chromosomal AmpC-producing Enterobacteriaceaes as well $(3,14)$. bla $a_{\mathrm{MIR}}$ and $b l a_{\mathrm{ACT}}$ previously were thought to be 85 to $87 \%$ identity with most chromosomal AmpC enzymes in E. cloacae (15). However, conjugative plasmid-mediated $b l a_{\mathrm{MIR}}$ and $b l a_{\mathrm{ACT}}$ were detected in E. cloacae in our study, which were rarely reported before.

Several researches have shown a close association between pAmpCs and ESBLs (3). We observed that a total of 23 isolates can produce both pAmpCs and $\beta$-lactamases simultaneously, which is in accordance with previous reports. The coexistence of different classes of $\beta$-lactamases in a single isolate can cause failure of treatment because these combinations restrict the range of available therapeutic options to some extent (16). ISCR1 elements have been found adjacent to a number of cephalosporinase genes, including class A 
$\beta$-lactamase genes especially CTX-M and class C $\beta$-lactamase such as DHA, CMY and MOX (17). ISCRI appears to be unusual in the sense that it is almost always found in a complex class 1 integron structure, which has been the most prevalent combination in our study. We found that all ISEcPl-positive isolates produce both intII integrase gene encoded in a class 1 integron and ISCRI. In a recent study by Bae Ik et al, it was shown that a $b l a_{\mathrm{CTX}-\mathrm{M}-14}$ gene was found on a complex class 1 integron and proceeded by a partial copy of ISEcpl in addition to a complete copy of ISCRI element in E. coli contained $3 \beta$-lactamase genes including $b l a_{\mathrm{DHA}-1}, b l a_{\mathrm{SHV}-12}$, and $b l a_{\mathrm{CTX}-\mathrm{M}-14}(18)$. It can be that this new complex class integron composed of parts of a new ISCR I/ISEcpl-associated fragment may have occurred among these pAmpC-producing isolates in China. The various antibiotic resistance genes existing in the same isolate can be carried by different mobile elements. Moreover, several studies have demonstrated that the ISEcpl or ISCR element appeared to act as a strong activator for $b l a_{\mathrm{CTX}-\mathrm{M}}$ gene expression (19). Since 16 transconjugants containing CTX-M type beta-lactamases, it would be possible that plasmids carrying $b l a_{\mathrm{CTX}-\mathrm{M}}$ are responsible for transferability. blaampC from chromosome jumped into plasmids carrying $b l a_{\mathrm{CTX}-\mathrm{M}}$, which lead to the result of plasmid-mediated transferring blaampC.

In conclusion, this is the first report describing the prevalence of pAmpCs among chromosomal AmpC-producing isolates. The concurrent occurrence of $\beta$-lactamases and the frequent association with mobile genetic elements, indicate a complex antibiotic resistance mechanism in these Enterobacteriaceaes. In our study, although plasmids were demonstrated to be the main vehicles for the dissemination of $\mathrm{pAmpC}$ genes among different bacteria, various mobile genetic elements may also play an important role in the prevalence of these enzymes. 


\section{ACKNOWLEDGMENTS}

The study was supported by National Natural Science Foundation of China (No. 81373072).

We thank all the contributing hospitals which provided isolates for this study.

\section{AUTHORS' NOTE}

There are competing interests and no need to ethical approval.

\section{REFERENCES}

1. Essack SY. The development of beta-lactam antibiotics in response to the evolution of beta-lactamases. Pharm Res 2001; 18: 1391-9.

2. Jacoby, GA. AmpC beta-lactamases. Clin Microbiol Rev 2009; 22: 161-82.

3. Iabadene H, Messai Y, Ammari H, Alouache S, Verdet C, Bakour R, Arlet G. Prevalence of plasmid-mediated AmpC beta-lactamases among Enterobacteriaceae in Algiers hospitals. Int J Antimicrob Agents 2009; 34: 340- 2.

4. Yang HF, Cheng J, Hu LF, Ye Y, Li JB. Plasmid-mediated quinolone resistance in extended-spectrum-beta-lactamase- and AmpC beta-lactamase-producing Serratia marcescenss in China. Antimicrob Agents chemother 2012; 56: 4529- 31.

5. Wei Y, Wang J. Identification of ACT-1 plasmid-mediated AmpC beta-lactamase producing Citrobacter freundii from a Chinese patient. Ann Lab Med 2013; 33: 86-8.

6. Mata C, Miró E, Alvarado A, Garcillán-Barcia MP, Toleman M, Walsh TR, de la Cruz F, Navarro F. Plasmid typing and genetic context of AmpC beta-lactamases in Enterobacteriaceae lacking inducible chromosomal ampC genes: findings from a Spanish hospital 1999-2007. J Antimicrob Chemother 2012; 67, 115-22.

7. Toleman MA, Walsh TR. Combinatorial events of insertion sequences and ICE in 
Gram-negative bacteria. FEMS Microbiol Rev 2011; 35: 912-35.

8. Clinical and Laboratory Standards Institute. Performance standards for antimicrobial susceptibility testing; twenty-fourth informational supplements, M100-S24. 2014; Wayne, PA: CLSI.

9. Barguigua A, El Otmani F, Talmi M, Bourjilat F, Haouzane F, Zerouali K, Timinuouni M. Characterization of extended-spectrum beta-lactamase-producing Escherichia coli and Klebsiella pneumoniae isolates from the community in Morocco. J Med Microbiol 2011; 60: 1344-52.

10. Black JK, Thomson KS, Pitout JDD. Use of beta-lactamase in-hibitors in disk tests to detect plasmid-mediated AmpC beta-lactamase. J Clin Microbiol 2004; 42: 2203-6.

11. Perez-Perez FJ, Hanson ND. Detection of plasmid-mediated AmpC beta- lactamase genes in clinical isolates by using multiplex PCR. J Clin Microbiol 2002; 40: 2153-62.

12. Wang F, Wu K, Sun J, Wang Q, Chen Q, Yu S, Rui Y. Novel ISCRl-linked resistance genes found in multidrug-resistant gram-negative bacteria in southern China. Int $\mathbf{J}$ Antimicrob Agents 2012; 40: 404-8.

13. Poirel L, Decousser JW, Nordmann P. Insertion sequence ISEcp 1B is involved in expression and mobilization of a bla (CTX-M) beta-lactamase gene. Antimicrob Agents Chemother 2003; 47: 2938-45.

14. Li Y, Li Q, Du Y, Jiang X, Tang J, Wang J, Li G, Jiang Y. Prevalence of plasmid-mediated AmpC beta-lactamases in a Chinese university hospital from 2003 to 2005: first report of CMY-2-Type AmpC beta-lactamase resistance in China. J Clin Microbiol 2008; 46, 1317-21.

15. Philippon A, Arlet G, Jacoby GA. Plasmid-determined AmpC-type beta- lactamases. 
Antimicrob Agents Chemother 2002; 46: 1-11.

16. Song W, Moland ES, Hanson ND, Lewis JS, Jorgensen JH, Thomson KS. Failure of cefepime therapy in treatment of Klebsiella pneumoniae bacteremia. J Clin Microbiol 2005; 43: 4891-4.

17. Toleman MA, Bennett PM, Walsh TR. ISCR Elements: novel Gene-Capturing Systems of the 21st Century? Microbiol Mol Biol REV 2006; 70: 296-316.

18. Bae Ik, Lee YH, Jeong HJ, Hong SG, Lee SH, Jeong SH. A novel bla(CTX-M-14) gene-harboring complex class 1 integron with an In4-like backbone structure from a clinical isolate of Escherichia coli. Diagn Microbiol Infect Dis 2008; 62: 340-2.

19. Zhao WH, Hu ZQ. Epidemiology and genetics of CTX-M extended-spectrum beta-lactamases in Gram-negative bacteria. Crit REV Microbiol 2013; 39: 79-101. 
Table 1. MICs range for $\mathrm{pAmpC}$ producers and their transconjugants

\begin{tabular}{|c|c|c|c|c|c|c|c|c|c|c|c|c|c|c|c|c|}
\hline $\begin{array}{l}\text { Organism (the number } \\
\text { of bacteria) }\end{array}$ & $\begin{array}{c}\text { MIC } \\
\text { range } \\
(\mathrm{CTX}) \\
\end{array}$ & $\begin{array}{l}\mathrm{MIC}_{50} \\
(\mathrm{CTX})\end{array}$ & $\begin{array}{c}\mathrm{MIC} \\
\text { range } \\
(\mathrm{CAZ})\end{array}$ & $\begin{array}{l}\mathrm{MIC}_{50} \\
(\mathrm{CAZ})\end{array}$ & $\begin{array}{c}\text { MIC } \\
\text { range } \\
(\mathrm{FOX}) \\
\end{array}$ & $\begin{array}{l}\mathrm{MIC}_{50} \\
(\mathrm{FOX})\end{array}$ & $\begin{array}{c}\text { MIC } \\
\text { range } \\
(\mathrm{FEP}) \\
\end{array}$ & $\begin{array}{l}\mathrm{MIC}_{50} \\
\text { (FEP) }\end{array}$ & $\begin{array}{c}\text { MIC } \\
\text { range } \\
(\mathrm{IPM}) \\
\end{array}$ & $\begin{array}{l}\mathrm{MIC}_{50} \\
\text { (IPM) }\end{array}$ & $\begin{array}{c}\text { MIC } \\
\text { range } \\
(\mathrm{TZP}) \\
\end{array}$ & $\begin{array}{l}\mathrm{MIC}_{50} \\
(\mathrm{TZP})\end{array}$ & $\begin{array}{c}\text { MIC } \\
\text { range } \\
(\mathrm{AMK}) \\
\end{array}$ & $\begin{array}{l}\mathrm{MIC}_{50} \\
(\mathrm{AMK})\end{array}$ & $\begin{array}{c}\mathrm{MIC} \\
\text { range } \\
(\mathrm{CIP}) \\
\end{array}$ & $\begin{array}{l}\mathrm{MIC}_{50} \\
(\mathrm{CIP})\end{array}$ \\
\hline E. cloacae (54) & $8->512$ & 256 & $8->256$ & 128 & $64->256$ & 256 & $0.25-32$ & 16 & $<0.25-32$ & 0.5 & $2->512$ & 64 & $1->512$ & 256 & $0.06->32$ & 16 \\
\hline S. marcescens (5) & $8->512$ & 256 & $8->256$ & 128 & $64->256$ & 256 & $0.25-32$ & 16 & $<0.25-32$ & 0.5 & $2->512$ & 64 & $1->512$ & 256 & $0.06->32$ & 16 \\
\hline C. freundii (4) & $8->512$ & 256 & $8->256$ & 128 & $64->256$ & 256 & $0.25-32$ & 16 & $<0.25-32$ & 0.5 & $2->512$ & 64 & $1->512$ & 256 & $0.06->32$ & 16 \\
\hline E.coli $\mathrm{J} 53 \mathrm{AZ}^{\mathrm{R}}$ & 0.25 & - & 0.25 & - & 0.5 & - & $<0.25$ & - & $<0.25$ & - & 0.25 & - & 0.25 & & 0.01 & - \\
\hline T-E. cloacae $^{1}(46)$ & $0.5-512$ & 128 & $0.5-256$ & 64 & $4-256$ & 256 & $<0.25-32$ & 16 & $<0.25-16$ & 0.5 & $0.5-512$ & 32 & $0.5->512$ & 256 & $0.06-0.5$ & 0.25 \\
\hline T-S. marcescens (5) & $0.5-512$ & 128 & $0.5-256$ & 64 & $4-256$ & 256 & $<0.25-32$ & 16 & $<0.25-16$ & 0.5 & $0.5-512$ & 32 & $0.5->512$ & 256 & $0.06-0.5$ & 0.25 \\
\hline $\mathrm{T}-C$. freundii (2) & $0.5-512$ & 128 & $0.5-256$ & 64 & $4-256$ & 256 & $<0.25-32$ & 16 & $<0.25-16$ & 0.5 & $0.5-512$ & 32 & $0.5->512$ & 256 & $0.06-0.5$ & 0.25 \\
\hline
\end{tabular}

1. T-E. cloacae was transconjugant from E. cloacae.

Table 2. The genotypes of $\mathrm{pAmpC}$ producers and their transconjugants

\begin{tabular}{rcccccc}
\hline genotypes & $\mathrm{p}$ E. cloacae (54) & $\mathrm{p}$ S. marcescens (5) & $\mathrm{p}$ C. freundii (4) & $\mathrm{T}_{\text {-E. }}$ cloacae $(51)^{2}$ & $\mathrm{~T}_{\text {-S. marcescens (5) }}$ & T-C. freundii (4) \\
\hline DHA-1 & 32 & 4 & 3 & 30 & 4 & 3 \\
ACT-1 & 22 & 1 & 1 & 21 & 1 & 1 \\
\hline
\end{tabular}

1. $\mathrm{p}$ E. cloacae was pAmpCs producers from E. cloacae.

2. T-E. cloacae was transconjugant from E. cloacae. 
Table 3. Distribution of other $\beta$-lactamases among 23 pAmpC E. cloacae and 19 transconjugants from pAmpC E. cloacae

\begin{tabular}{|c|c|c|}
\hline pAmpC producers & genotypes & transconjugants from \\
\hline No.3 & CTX-M-14/DHA-1 & No.3 \\
\hline No. 15 & OXA-1/DHA-1 & No.15 \\
\hline No. 22 & TEM-1/ACT-1 & $-{ }^{\mathrm{a}}$ \\
\hline No.29 & SHV-5+CTX-M-14/DHA-1 & No.29 \\
\hline No.65 & TEM-1/DHA-1 & No.65 \\
\hline No.78 & CTX-M-14/ACT-1 & $-{ }^{a}$ \\
\hline No.109 & TEM-1+CTX-M-14/ACT-1 & No.109 \\
\hline No.134 & TEM-1+CTX-M-14/DHA-1 & No.134 \\
\hline No.166 & CTX-M-15/ACT-1 & No.166 \\
\hline No.195 & SHV-5/DHA-1 & No.195 \\
\hline No.211 & SHV-5+CTX-M-14/DHA-1 & No.211 \\
\hline No.252 & CTX-M-14/ACT-1 & No.252 \\
\hline No.284 & TEM-1+CTX-M-14/DHA-1 & No.284 \\
\hline No.302 & TEM-1+SHV-5/DHA-1 & $-{ }^{a}$ \\
\hline No.315 & CTX-M-14/ACT-1 & No.315 \\
\hline No.336 & SHV-5+CTX-M-14+OXA-1/DHA-1 & No.336 \\
\hline No.362 & TEM-1+CTX-M-14/DHA-1 & No.362 \\
\hline No.390 & CTX-M-15/DHA-1 & No.390 \\
\hline No.413 & TEM-1+CTX-M-14+OXA-1/DHA-1 & No.413 \\
\hline No.445 & CTX-M-15/DHA-1 & No.445 \\
\hline No.491 & SHV-5+CTX-M-14/DHA-1 & No.491 \\
\hline No.502 & SHV-5+CTX-M-14/DHA-1 & No.502 \\
\hline No.527 & TEM-1+SHV-5/ACT-1 & $-^{\mathrm{a}}$ \\
\hline
\end{tabular}

a Conjugation was not performed successfully. 